\title{
Comparison of Pilot Recovery and Response Times in Two Types of Cockpits
}

\author{
Vishal Hiremath ${ }^{1}$, Robert W. Proctor ${ }^{2}$, Richard O. Fanjoy ${ }^{3}$, Robert G. Feyen ${ }^{4}$, \\ and John P. Young ${ }^{3}$ \\ ${ }^{1}$ Gulfstream Aerospace Corp., 500 Gulfstream Road, M/S B-16 \\ Savannah, GA 31407, USA \\ ${ }^{2}$ Department of Psychological Sciences, Purdue University, 703 Third Street, \\ West Lafayette, IN 47907, USA \\ ${ }^{3}$ Department of Aviation Technology, Purdue University, 1401 Aviation Drive, \\ West Lafayette, IN 47907, USA \\ ${ }^{4}$ Department of Mechanical and Industrial Engineering, University of Minnesota - Duluth, 1305 \\ Ordean Court, Duluth MN 55812-3042 \\ vishal.hiremath@gmail.com, \{rproctor, rofanjoy, jpy\} @purdue.edu, \\ rfeyen@d.umn.edu
}

\begin{abstract}
According to general aviation manufacturers, all aircraft rolling off the assembly line are or will be equipped with next-generation electronic flight instrument cockpits, called 'glass' cockpits. Because most pilots were trained with older analog displays, it becomes imperative to find out what human factors issues the pilots will encounter when they transition to glass displays. A comparative study was carried out in a general aviation aircraft simulator between instrumentation of the type used in conventional and glass cockpits for recovery from unusual attitudes. Glass displays showed longer recovery time than round-dial displays. Low-time pilots judged analog displays as more usable than glass displays. Suggestions are made to design a hybrid display of round dial and vertical tapes as well as examine unusual attitude training methods more closely.
\end{abstract}

Keywords: glass cockpits, displays, digital displays, aviation, analog displays.

\section{Introduction}

Accident rates for advanced-technology aircraft are lower than for comparable conventional aircraft. Nevertheless, pilots, scientists, and aviation safety experts have expressed concerns about flight deck automation: Pilots may place too much confidence in automation, they may lose manual flying skills, and pilot-automation interfaces may be poorly designed [1]. Recent accidents involving advanced-technology aircraft have served to emphasize those concerns.

An example of automation error that has implications for the general aviation industry bears noting - the American Airlines accident in Cali, Columbia [2, 3]. A programming error in the aircraft flight management system (FMS) led the aircraft 
automation to mistake one navigation beacon for another. This caused a change in heading that went unnoticed by the crew, resulting in impact with the side of a mountain. Unlike many general aviation pilots, these professional pilots flew often and received recurrent training in the use of their equipment. This accident was found to be the result of an aircraft FMS interface error and lack of pilot situational awareness problems often experienced in commercial and general aviation [4]. Research has suggested that problems in airline pilot transition to glass cockpits may also apply to general aviation aircraft [5].

Between $70 \%$ and $80 \%$ of aviation accidents can be attributed, in part, to human error [6]. This error frequently reflects pilot confusion due to ambiguous cockpit displays or misinterpretation of automated flight modes. In recent years, research into airline cockpit design has served to make displays more usable. More recently, computerized cockpits with advanced-technology displays have become popular in general aviation aircraft.

General aviation is dominated by pilots who fly for recreation, with most having little flight time compared to airline pilots. As new glass cockpits are introduced to general aviation, there are lessons to be learned from similar equipment in airline category aircraft. A particular area where pilots have had problems with glass cockpit instrumentation is the vertical tape display used to show airspeed and altitude. Collins [7] illustrates examples of different kinds of instrumentation such as vertical tapes and graphical navigation displays. During initial training, most pilots used airspeed indicators and altimeters with round-dial presentations. When they transition to more advanced aircraft with linear-tape displays, they may find it difficult to adapt to such displays. The present study compared performance of general aviation pilots when using linear-tape and round-dial displays to identify differences in performance with the two display types.

\section{Problem Statement}

Advances in aircraft instrumentation have led to highly integrated instrument displays. Prior research suggests that general aviation pilots may have difficulty with the interpretation of advanced displays, which can lead to a lack of situational awareness [4]. The problem addressed by the present study was how pilots respond to new glass displays during an emergency such as upset recovery, after learning to fly in older airplanes.

This research was conducted in response to increasing sales of integrated glass cockpits in general aviation. Prior research into advanced displays of transport aircraft suggests safety concerns for general aviation counterparts. In this study, we used flight scenarios of unusual attitudes to evaluate this difference in performance, since accident reports show that a majority of fatal general aviation accidents are caused by flight from Visual Meteorological Conditions into Instrument Meteorological Conditions, with resulting spatial disorientation [8]. When pilots lose visual cues they must rely on their instruments to maintain safe flight. Avionics companies claim that simpler, user-friendly displays help pilots maintain situational awareness. The present research addresses that claim. 
The current study analyzed whether training in unusual-attitude recovery and basic flight instrumentation will help pilots cope with advanced-technology cockpits. The method was based on those used in several previous studies. Beringer et al. [9] described a method of analyzing different displays during recovery from unusual attitudes and conducted a multivariate analysis to determine whether displays superimposed with terrain images had an effect on pilot performance. Their project evaluated the time for recovery, which ends at the time instant of recovery (the time when the airplane reaches a level flight attitude) plus three seconds. The additional three seconds is to confirm a steady recovery state. The present study emulated this convention. Liggett and Venero [8] tested nine military pilots for response time in three different types of displays during recovery from unusual attitudes. The three displays were a standard 2-dimensional Primary Flight Display (PFD), PFD with an auditory display, and a PFD with a 3-dimensional display. Casner [10] describes an experiment to investigate usability and training issues when teaching students to fly GPS approaches. His methodology used two groups of pilots to fly scenarios using two different learning techniques. The instructor occupied the right seat and controlled the experiment, a procedure used in the present study.

Pilots were put into an unusual attitude by the experimenter, from which they had to recover. This was done with both simulated glass and analog displays. The prediction was that time to the initial response (response time) and time to recover (recovery time) would be longer when flying the simulated glass display than with the analog display. This prediction was based on human factors literature mentioned in the above paragraph suggesting that glass displays are not the best way to convey information.

\section{Method}

A research platform was developed and housed in an aircraft shell. Two computers were networked to run in parallel with two monitors connected to each system. This network allowed flight simulation software in both computers to be linked together with identical software and depended on the network feature of X-plane to move data quickly between the computers. Each computer was connected to two monitors by a cable that splits the signal from each computer to display the image on both monitors. One computer was configured to display the instrument panels, and the other to display the external view (see Fig. 1).

For the external view, two 19-in. flat CRT monitors were mounted outside the shell, just outside the forward windows. External images were spread across the two monitors to present the simulated outside world visible from the cockpit. For the in-cockpit view, two 17-in. monitors were fitted into the instrument panel, one on each side of the cockpit, to present the simulated electronic and analog displays.

Participants were presented with simulated emergency situations requiring recovery from unusual attitudes. Two main forms of data were gathered: (1) pilots' performance while flying the simulator to recover from the unusual attitudes; (2) information gathered from the pilots regarding their perceptions of the ease and usability of the different instrument configurations. These data were obtained through a post flight questionnaire. 


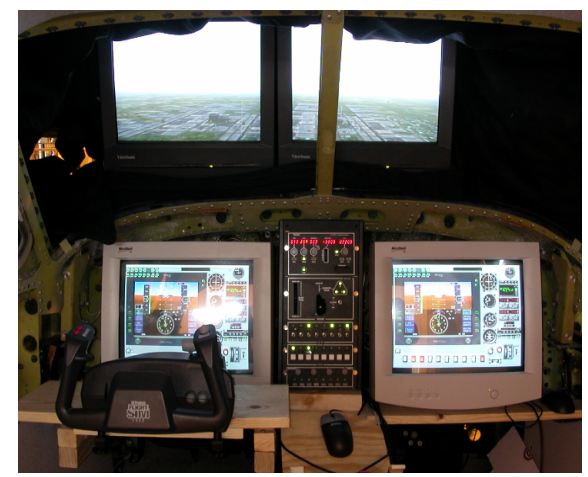

Fig. 1. Simulator display set-up

The independent variable was type of cockpit display: (1) conventional round-dial (analog) instrumented display or (2) new glass cockpit display with vertical tape altitude and airspeed representation. Recovery time and response time were dependent variables. Recovery time was defined as the time taken by a pilot to recover the aircraft from the simulated unusual attitude to a safe attitude. A safe attitude was attained when the aircraft had returned to level flight and was stabilized at target airspeed. If the aircraft was within $+/-5^{\circ}$ of bank, $+/-5^{\circ}$ of pitch and 90 knots $+/-5$ knots, the aircraft was considered to be in a recovered state. Recovery time was captured from the data output page generated by the flight simulator software. As soon as all three conditions defining a safe state were satisfied, the corresponding elapsed time was noted and recorded as the recovery time for that trial. Response time was defined as the time taken by the pilot to make the first response, either with the control yoke or the throttle. Response time was captured by flight simulator software that calculated the rate of change of flight controls.

Eighteen flight students (12 male and six female) who had earned their private pilot license but had not received instrument rating were recruited as participants. Their mean flying time was $119 \mathrm{hrs}$, and average age was 21 years. The order in which the participants received the simulated events during the flight profile was randomized so that participants would not be able to anticipate the sequence of maneuvers. All participants flew the scenarios with both displays. Half the participants flew the analog cockpit first and the glass cockpit second, and half flew the glass first and analog second. The specific experimental group to which the participants were assigned was determined randomly.

Each participant was exposed to four unusual attitude scenarios: nose high/wings level, nose low/wings level, nose high/steep left bank and nose low/steep right bank. The scenarios were representative of unusual attitudes experienced by general aviation pilots during loss of control events. Each attitude consisted of pre-established pitch $\left(+/-30^{\circ}\right)$ and bank $\left(+/-45^{\circ}\right)$ angles selected by the researcher. Predefined tolerance limits for the upset configuration were $+/-5^{\circ}$ pitch and $+/-5^{\circ}$ bank. If the aircraft was within these limits it was considered established in the simulated unusual attitude.

Initial trials were carried out to validate simulator operation, gather initial data to estimate participant standard deviation, and refine the methodology. Five flight 
students volunteered to test fly the simulator and offer feedback. Their responses indicated that the control sensitivity needed to be adjusted. The fidelity of the device was validated by four flight instructors who test flew the simulator to determine how well it replicated flight performance parameters. The Director of Safety of the Aviation Technology Flight Department, an experienced pilot and instructor, flew the simulator and gave feedback on the system. He expressed satisfaction with the handling of the simulator, but noted its limitations with regard to feel and motion. The flight instructors who test flew the simulator agreed that it was adequate to simulate real airplane behavior, consistent with the software manufacturer's statement that the aerodynamic flight model of the airplane is similar to a real aircraft. Based on the feedback, the simulator software and controls were refined and adjusted to improve similarity to real airplane performance. The initial trials were conducted in the exact same way as the actual experiment was done. Data were collected, and the mean and standard deviation of recovery times were calculated. These were then used to calculate sample size for the main experiment. Participants in the pilot study had, on an average, 200 more hours of flight time than those in the main experimental group. Other factors, like age range and educational experience, were similar.

A questionnaire, which asked for demographic data about total flying hours, gender, and age, was given to participants after they completed the simulator trials. Participants were also asked to describe the procedure that they would use to recover from an unusual attitude. This was followed by six questions for which participants responded with a rating of 1 (easy) to 5 (difficult): how easy it was to recognize present (a) airspeed and (b) rate of change of airspeed with a vertical tape airspeed indicator and with a round dial indicator, and how difficult it was to recover using each display indicator. Finally, four open-ended questions asked what features of the glass display they liked and disliked, which design features they would modify, and thoughts about the display color coding that was used.

\subsection{Experimental Protocol}

Step 1. Simulator operation was explained to the participants, who then flew the simulator for $10 \mathrm{~min}$ to get familiar with its operation. During this time, they were asked to climb $500 \mathrm{ft}$ with full power and level off. Then they were asked to do a left $30^{\circ}$ banking turn to a heading of $90^{\circ}$ from the original heading and recover to a wings level state. They were then asked to perform a right $30^{\circ}$ banking turn to a $90^{\circ}$ heading from the original heading and descend $500 \mathrm{ft}$ with idle power and level off. Finally, a stall entry and recovery was performed. These practice maneuvers were repeated once with each display.

Step 2. After the practice flight, the researcher began the trial and asked the participant to accelerate to a speed of 90 knots. He then asked the participant to put on an instrument flying hood provided by the researcher. The participant was asked to release the yoke and locate an airfield on a map. While the participant was looking for the airfield, the researcher took control of the yoke and put the aircraft in an unusual attitude.

Step 3. As soon as the aircraft reached the predetermined upset attitude, the researcher released the yoke, which returned to its neutral position. Initial trials indicated that 
there was a slight change in aircraft attitude when the yoke returned to the neutral position but that it stayed within the predefined tolerance levels $\left(+/-5^{\circ}\right.$ pitch and bank) for the scenario.

At this point the researcher said, "Recover to level flight and 90 knots." This indicated that the participant was to look up, perceive his present attitude, and begin the recovery. At the time the researcher alerted the participant, recovery time measurement was initiated. If the participant did not respond immediately to the instructor, the trial was rerun.

Step 4. As soon as the participant brought the aircraft within the recovery envelope (+/- 5 degrees of pitch and +/- 5 degrees of bank and 90 knots +/- 5 knots), the researcher terminated the recovery time measurement. An electrical toggle switch hooked to the simulator was utilized in order for the software to capture the recovery time parameter and make it available on the software output page for analysis.

Data Analysis. Recovery time was obtained by subtracting the time when the aircraft was recovered from the trial start time. Response time was obtained by calculating the rate of change of yoke and throttle. The first significant change in flight control movement time minus the initial trial start time was the response time.

\section{Results}

Mean recovery times for the two display designs in the four flight scenarios are presented in Fig. 2. There was neither a main effect for scenarios nor interaction with display design, $F \mathrm{~s}(3,136) \leq 1.43, p \mathrm{~s} \geq .24$. However, the main effect of display design was significant, $F(1,136)=7.977, p<.05$, indicating that the pilots recovered in shorter time for the analog cockpits across all unusual flight situations.

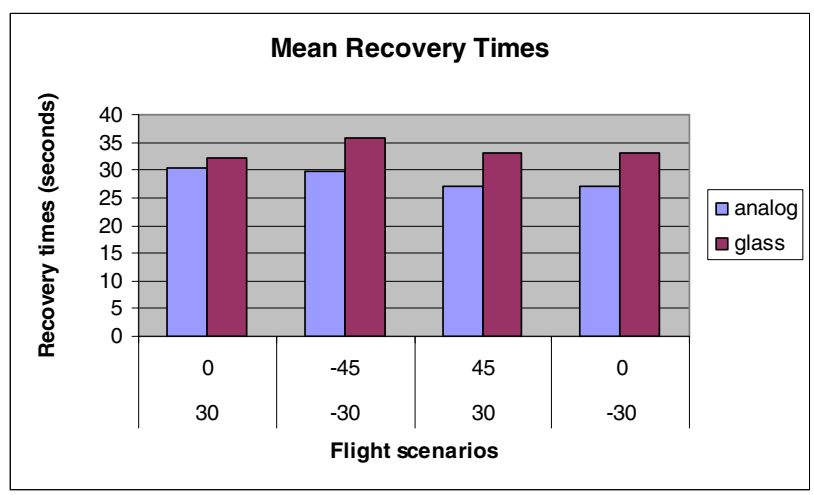

Fig. 2. Mean recovery times (bank $+/-30^{\circ}$; pitch $+/-45^{\circ}$ )

The mean response time as a function of the two factors is presented in Fig. 3. The ANOVA did not indicate any significant effects on response time, $F$ s $<1$. 


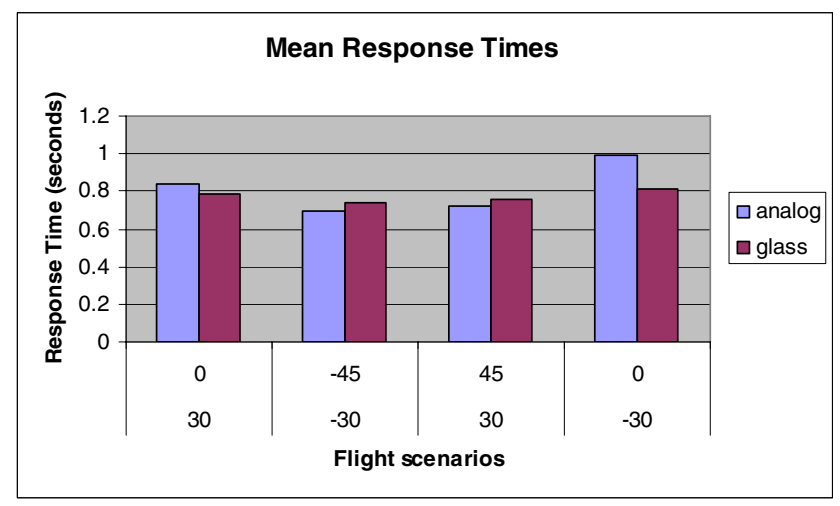

Fig. 3. Mean response times (bank $+/-30^{\circ}$; pitch $+/-45^{\circ}$ )

For the questionnaire, there was no significant difference in responses to the questions of which airspeed indicator was easier to interpret, although there was a tendency for the round dial display to be judged as easier $(M=1.5)$ than the tape indicator $(M=2.0), \mathrm{p}=.11$. For rate of change of airspeed, the difference between the analog and glass airspeed indicators was significant, $p<.025$ : Analog dials $(M=1.5)$ were rated as easier than glass tapes $(M=2.3)$. Although round dials tended to be rated as better for judging airspeed and airspeed trend, for the questions about how easy or difficult it was to recover, there was no significant difference between the round-dial $(M=1.78)$ and linear-tape $(M=1.67)$ displays. Analysis of the open-ended questions showed the following.

List recovery step by step. The three major recovery components mentioned by the participants were throttle adjustment, level wings, and return to flight attitude. $89 \%$ of the respondents mentioned throttle adjustment, and $94 \%$ mentioned recovery to level wings and pitch to safe attitude. Determining spatial orientation before initiating recovery action was mentioned by $44 \%$ of respondents.

What features did you most like about the glass cockpit? The feature the respondents liked was the relatively large attitude and direction indicator, also known in industry as the coast-to-coast artificial horizon because it stretches from one end of the display to the other. This instrument makes it very easy to recognize attitude and was listed by $77 \%$ of the respondents. Other significant items mentioned were the precise values of airspeed and altitude obtained from the digital tape readouts $(38 \%$ of the respondents conveyed this).

What features did you not like about the new display? The vertical airspeed tape was disliked by $38 \%$ of respondents. They mentioned that it is difficult to spot an airspeed trend when the tape was moving, unlike a round dial. About $33 \%$ of the respondents said that they did not like the vertical altitude tape because they were unable to view the whole altitude range. They also found it difficult to differentiate between up or down movement.

What do you think of the color coding used? Overall, most respondents were satisfied with the color coding. 
What design features do you want changed or modified? A design change was needed, in the vertical airspeed and altimeters tapes, according to $38 \%$ of the respondents. Their opinion was that it is hard to get a value in a quick scan, which makes it difficult to get trend information quickly. This is because, in a round dial display the pilot gets an idea of his or her airspeed just by looking at the position of the needle. For example, if the needle is in the 3:00 position the airspeed is low. This quick information is not provided on a vertical tape. Another interesting recommendation of participants was to design a display that grows in size as airspeed increases. This is in the form of an inverse trapezoid where the width at the top increases as airspeed increases, which might help in easier identification of speed. Some participants also found it difficult to read the altimeter and suggested that it be marked in hundreds of $\mathrm{ft}$ so that they would get a better sense of the approaching altitude.

\section{Discussion and Recommendations}

Analysis of the flight simulation data indicated that recovery times were significantly longer for the glass cockpit display than for the round-dial display, which suggests that glass cockpit displays may not as beneficial for pilot performance as has been claimed. Because pilots are qualified to fly glass cockpits without extensive training, more attention is needed towards training or a modification of the design to allow for easier operation. There was no statistically significant difference in response times for all flight scenarios. A possible explanation for difference in recovery time for the pitch down scenarios might be elevated stress levels when pilots realize that they were flying towards the ground and therefore directed less attention to desired airspeed. It may be that in an emergency situation like an upset, pilots find it harder to read tape displays than analog dials. Analog dials seem to be easier to read than glass displays because the position of the needle relative to the whole range of numbers in the airspeed indicator can be picked out at a quick glance. In the glass display the whole range is not visible, so, to get an idea of the airspeed, the pilot has to focus longer on the numerical readout to perceive the airspeed.

A majority of respondents included the essential functions or steps that needed to be accomplished during an unusual attitude recovery. All participants completed most of the aircraft attitude upset recovery steps. None of the participants crashed the simulated airplane. Most airlines use a recovery technique that includes adjusting pitch, roll rate, thrust settings and leveling the aircraft [12]. Most of the study participants mentioned these steps in their responses. However, there was no particular order or consistency in the steps. This suggests that training does not emphasize the order of the steps as much as the general recovery. The sequence of recovery may be an interesting issue for further investigation.

There was a significant difference between the two types of displays for questions involving the ease of airspeed trend recognition. This difference suggests that participants had a greater problem comprehending changing airspeed with the vertical tape than with the round dial airspeed indicator. Human factors literature also suggests that moving tapes are not the best way to display rate of change of information. There is a need to redesign this aspect of the glass cockpit. At the medium-level altitude used in this study, trend comprehension may be relatively unimportant but during critical phases 
of flight like approaches, landings, takeoffs and emergencies, trend comprehension might mean the difference between safe activity and a mishap.

The majority of respondents liked the big and colorful indication of the glass cockpit ADI or artificial horizon that gave them a good indication of their situation awareness. They also liked the digital readouts of the glass cockpit tapes but did not like their reduced ability to convey trend information. This suggests that current glass cockpit flight displays enhance situational awareness over older versions. Tape displays received a mixed response from pilots who liked the exact information regarding airspeed and altitude but disliked poor trend information. A redesign of glass displays is needed to improve access to trend information that leads to improved safety and situational awareness.

The most common suggestion by participants was that the vertical tape airspeed and altimeters should be redesigned to benefit low-time pilots transitioning from round dial instrumentation. One solution is to combine precise readouts of tape displays with trend information depicted on round dials in a hybrid display that uses both features. The resulting display can be color coded to show the approximate speed (like in a pie chart) with a digital readout beneath the display (Fig. 4). A suggested design is for the airspeed tape to be converted to a round dial display with a pink color to indicate present airspeed. This presentation gives the pilot an idea of the current airspeed at a glance. If the exact value is needed, the pilot can refer to the box beneath the display for precise readout. The outside circumference of the airspeed dial will be labeled with numbers like in traditional cockpits. We also recommend that a closer look be taken at unusual attitude and upset training for light airplanes. The fact that no two participants gave the same order for upset recovery suggests that training does not emphasize the order in which to recover. It might be a good idea to test participants trained in the exact order versus participants trained to recover the aircraft without particular attention to the order and compare their performance.

Future studies can investigate the following issues. Does age or gender have an effect on transition from analog to glass displays? Is there any difficulty in reverse transition back to gauge displays in general aviation? This is a potential problem since future pilots will learn to fly on glass but older airplanes will always be around. What is

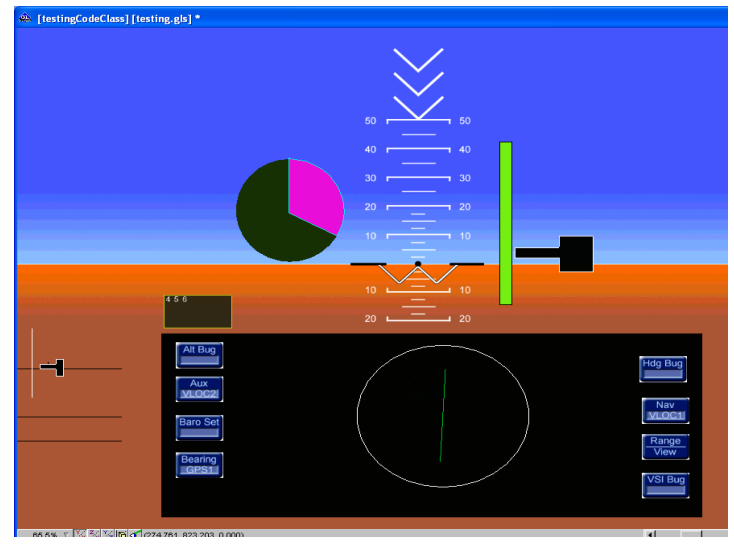

Fig. 4. Redesign recommendation 
the effect on performance during approach, landing or takeoff? In addition, newly developed small jets are being introduced with a flight management system. Like newer piston singles, they have more complicated navigation displays that require a lot of display programming to call up checklists and set navigation waypoints. With the advent of datalink in commercial aviation, it is only a matter of time before that enhancement adds further complexity to general aviation. Further research is needed to investigate the difference in recovery times with pitch down scenarios. There is also a need to investigate whether a redesigned display will improve performance and be accepted by future pilots.

\section{References}

1. Funk, K.H.: Cockpit Task Management: Preliminary Definitions, Normative Theory, Error Taxonomy, and Design Recommendations. Int. J. of Aviation Psychology 1, 271-285 (1991)

2. NTSB Abstract: Safety recommendations concerning the American Airlines 757 accident near Cali, Columbia, December 20, 1995 (1996),

http: / /www.rvs. uni-bielefeld.de/publications / Incidents / DOCS / ComAndRep/Cali /NTSB/COPY/961001.htm (downloaded Feburary 22, 2009)

3. Gerdsmeier, T., Ladkin, P., Loer, K.: Analyzing the Cali Accident with a WB-Graph. Paper presented at the Human Error and Systems Development Workshop. Glasgow, UK (1997)

4. Adams, C.A., Hwoschinsky, P.V., Adams, R.A.: Analysis of adverse events in identifying GPS human factors issues. In: 11th International Symposium on Aviation Psychology (2001)

5. Lyall, B., Niemczyk, M., Lyall, R., Funk, K.: Flightdeck Automation: Evidence for Existing Problems. In: Proceedings of the 9th Int. Symp. on Av. Psychol., Columbus, OH (1997)

6. Shappell, S.A., Wiegmann, D.A.: The Human Factors Analysis and Classification SystemHFACS (DOT/FAA/AM-00/7).Virginia Office of Aviation Medicine: Washington, DC (2000)

7. Collins, R.: How to Avoid Deadly Distractions (2005), http://www. flyingmag . com/article.asp?article_id=522\&print_page=y (downloaded Feburary 7, 2005)

8. Liggett, K., Venero, P.: The Effects of Helmet-mounted Display Symbology on Flight Performance. In: Proceedings of Human Machine Systems Symposium, Atlanta, GA (2004)

9. Beringer, D.B., Ball, J.D., Brennan, K., Taite, S.: The Effect of Terrain-depicting Primaryflight-display Backgrounds and Guidance Cues on Pilot Recoveries from Unknown Attitudes. In: Proceedings of the 13th Int. Symp. on Av. Psychol., Oklahoma City, OK, pp. 46-51 (2005)

10. Casner, S.M.: Flying IFR with GPS: How Much Practice is Needed? Int. J. of Applied Aviation Studies 4, 81-97 (2004)

11. Proctor, R.W., Young, J.P., Fanjoy, R.O., Feyen, R.G., Hartman, N.W., Hiremath, V.V.: Simulating Glass Cockpit Displays in a General Aviation Flight Environment. In: Proceedings of the 13th International Symposium on Aviation Psychology, Oklahoma City, OK, pp. 481-484 (2005)

12. Schlimm, K.: Unusual attitude recovery: Reacting quickly in an over-banked situation, http: / / www . avweb. com/news / airman/190089-1.html (downloaded July 18, 2005) 